\title{
Establishment and characterization of novel human uterine leiomyosarcoma cell lines
}

\author{
TETSUJI TANAKA ${ }^{1}$, SAORI TOUJIMA ${ }^{1}$, SHINJI TOYODA ${ }^{2}$, SATORU TAKEUCHI $^{3}$ and NAOHIKO UMESAKI ${ }^{4}$ \\ ${ }^{1}$ Department of Obstetrics and Gynecology, Wakayama Medical University, 811-1 Kimi-idera, Wakayama 641-0012; \\ ${ }^{2}$ Division of Obstetrics and Gynecology, Nara Hospital, 1-30-1 Hiramatsu, Nara 631-0846; ${ }^{3}$ Department \\ of Obstetrics and Gynecology, Iwate Medical University, 19-1 Uchimaru, Morioka 020-8505; \\ ${ }^{4}$ Division of Gynecology, Izumi City Hospital, 4-10-10 Fuchu-cho, Izumi 594-0071, Japan
}

Received February 16, 2010; Accepted April 8, 2010

DOI: 10.3892/ijo_00000660

\begin{abstract}
Patients with unresectable advanced uterine leiomyosarcoma have a very poor prognosis because no effective chemotherapeutic protocols exist. There are currently few established primary human uterine leiomyosarcoma cell lines that can be used to investigate effective therapies. To overcome this problem, we carried out long-term in vitro cell culture and/or nude mouse transplantation and successfully established novel human uterine leiomyosarcoma cell lines from extrauterine and intrauterine tumors that were surgically excised from a single patient. The established cells were characterized by flow cytometry, anticancer drug-sensitivity assays and karyotyping analyses. All the established cell lines showed unstable multiple chromosome abnormalities. Since the cells can proliferate in vitro and in vivo, they will be useful for developing new therapeutic strategies for advanced uterine leiomyosarcoma patients.
\end{abstract}

\section{Introduction}

The clinical prognosis of patients with unresectable advanced uterine leiomyosarcoma is very poor because anticancer chemotherapy or radiotherapy for such tumors has almost no effects on reducing the tumor progression. The reasons for the lack of effective therapies are that clinical studies of various cancer treatments cannot be performed because patients with primary uterine leiomyosarcoma are very rare, and that few uterine leiomyosarcoma cell lines have been sufficiently established to be used in experimental studies investigating novel effective treatments for leiomyosarcoma. There are several possible reasons why only a few uterine

Correspondence to: Dr Tetsuji Tanaka, Department of Obstetrics and Gynecology, Wakayama Medical University, 811-1 Kimi-idera, Wakayama 641-0012, Japan

E-mail: obgywmu@wakayama-med.ac.jp

Key words: leiomyosarcoma, uterus, karyotype, drug sensitivity leiomyosarcoma cell lines have been established to date. First, it is very difficult to obtain primary uterine leiomyosarcoma tissue because of the rarity of the disease. Second, it can be very difficult to culture and maintain primary human uterine leiomyosarcoma cells in vitro. Finally, it may be very difficult to transplant and grow primary human uterine leiomyosarcoma cells stably in nude mice. In the present study, we obtained uterine leiomyosarcoma tissue from a patient that we treated and successfully established novel human uterine leiomyosarcoma cell lines that can grow in vitro and produce tumors in nude mice after transplantation.

\section{Materials and methods}

Patient and primary tumor cells. Primary leiomyosarcoma tumors were surgically resected from a 42-year-old patient with advanced uterine leiomyosarcoma. The patient died from the leiomyosarcoma at 3 months after the surgery even though anticancer chemotherapy was performed. Leiomyosarcoma tissues, obtained with written consent, from three extrauterine tumors and two intrauterine tumors were cultured in vitro or transplanted into nude mice, respectively. The tumor cells were examined by flow cytometry, anticancer drug-sensitivity assays and karyotyping analyses.

In vitro culture of leiomyosarcoma cells. Surgically resected leiomyosarcoma tumor cells were cultured in vitro as follows. The tissue samples were cut into small fragments with scissors and incubated in medium containing $0.1 \%(\mathrm{w} / \mathrm{v})$ collagenase (Wako Chemicals, Tokyo, Japan), $500 \mathrm{U} / \mathrm{ml}$ penicillin (Gibco BRL, Gaithersburg, MD, USA), $500 \mu \mathrm{g} / \mathrm{ml}$ streptomycin (Gibco BRL) and $1250 \mathrm{ng} / \mathrm{ml}$ amphotericin B (Gibco BRL) for $30 \mathrm{~min}$ at $37^{\circ} \mathrm{C}$. The digested tissues were centrifuged at $1500 \mathrm{rpm}$ for $6 \mathrm{~min}$ at $4^{\circ} \mathrm{C}$. The cell pellets were resuspended and cultured in OPTI-MEM (Gibco BRL), 5\% fetal calf serum (FCS) (Equitech Bio Inc., Ingram, TX, USA), $100 \mathrm{U} / \mathrm{ml}$ penicillin, $100 \mu \mathrm{g} / \mathrm{ml}$ streptomycin, $250 \mathrm{ng} / \mathrm{ml}$ amphotericin B and $3 \times 10^{-7} \mathrm{M}$ estradiol. Nude mouse tumor cells were cultured according to the same procedures as the primary tumor cells. For comparative studies, the well-known human leimyosarcoma cell line SKN (1) was cultured in the same culture media as the primary tumor cells. The SKN cell line was obtained from Riken Cell Bank (Tsukuba, Japan). Normal 
human endometrial stromal cells (ESCs) were obtained from a leiomyoma patient and cultured according to a previously reported method (2).

Limiting dilution analysis. To identify possible stem cell-like leiomyosarcoma cells among the in vitro-cultured primary uterine leiomyosarcoma cells, limiting dilution cultures were performed. Briefly, two independent cultures of primary tumor cells with $>99 \%$ viability were seeded at final cell densities of 40,8 and 1.6 cells/well in 96-well plates. Cultured nude mouse tumor cells were diluted and cultured in a similar manner. The details of our limiting dilution culture methods and the calculation of the cloning efficiency were described in our previous study (2).

Nude mouse transplantation. Mice were housed in the animal facilities of Wakayama Medical University. Our institutional Animal Ethics Review committee approved the experimental protocols. The first nude mouse transplantation was conducted with cultured leiomyosarcoma cells and resected leiomyosarcoma tissue specimens. After 5 days in vitro, adherent tumor cells were detached in $0.25 \%$ trypsin/ $1 \mathrm{mM}$ EDTA (Gibco BRL) and resuspended in $0.5 \mathrm{ml}$ of serum-free OPTI-MEM. Tumor cells were resuspended in medium containing $0.5 \mathrm{ml}$ of Matrigel (Sigma Chemical Co., St. Louis, MO, USA) and about $1 \times 10^{8}$ cells were injected intraperitoneally into 10-week-old female Balb/c nu/nu mice (Nihon Clea, Osaka, Japan). The fresh tissue specimens were transplanted subcutaneously onto the backs of three 10-week-old female Balb/c nu/nu mice.

The second nude mouse transplantation was conducted with tumor cells from the first tumor-bering mice as follows. Tumors were resected and cut into small fragments with scissors. Fresh fragments were transplanted subcutaneously into the backs of three female Balb/c nu/nu mice. At 2 months after the second transplantation, tumors had grown on the backs of all three mice.

Histopathology. After the tumor-bearing nude mice were anesthetized with ether and sacrificed by cervical dislocation, the tumors were excised. The tissue specimens were fixed in $10 \%$ formalin, dehydrated, embedded in paraffin and cut into sections. The sections were deparaffinized and stained with hematoxylin and eosin (HE) (Sigma Chemical Co.).

Flow cytometric analyses of cell surface antigens. Cells were detached from culture flasks with $3 \mathrm{mM}$ EDTA in phosphatebuffered saline (PBS), and immunostained as follows. The cells $\left(3 \times 10^{5}\right)$ were incubated with an excess of the primary antibody for $20 \mathrm{~min}$ at $4^{\circ} \mathrm{C}$ and then washed twice in wash buffer (PBS containing 2\% FCS and $0.1 \% \mathrm{NaN}_{3}$ ). Next, the cells were incubated in FITC-conjugated goat anti-mouse IgG (H+L) (Dako Japan, Kyoto, Japan) for $20 \mathrm{~min}$ at $4^{\circ} \mathrm{C}$ and washed twice in wash buffer. Finally, the cells were suspended in $200 \mu 1$ of wash buffer and analyzed using a FACSCalibur ${ }^{\mathrm{TM}}$ (Beckman Coulter Japan, Tokyo, Japan). The following primary antibodies were used: mouse anti-human CD29 monoclonal antibody (clone TDM29; Cymbus Biotech Ltd., Hampshire, UK); mouse anti-human CD30 monoclonal antibody (clone HRS-4; Immunotech, Marseille, France); mouse anti-human CD49a monoclonal antibody (clone TS2/7; Serotec Ltd., Oxford, UK); mouse anti-human CD34 monoclonal IgG (clone B1-3C5; Zymed Laboratories, San Francisco, CA, USA); mouse anti-human CD49b monoclonal antibody (clone 31H4; Serotec Ltd.); mouse anti-human CD49c monoclonal antibody (clone 11G5; Cymbus Biotech Ltd.); mouse anti-human CD49d monoclonal antibody (clone 44H6; Cymbus Biotech Ltd.); mouse anti-human CD49e monoclonal antibody (clone SAM1; Beckman Coulter Japan); mouse anti-human CD49f monoclonal antibody (clone 4F10; Cymbus Biotech Ltd.); mouse anti-human CD40 monoclonal antibody (clone MAB89; Beckman Coulter Japan); mouse anti-human Fas (CD95) monoclonal IgG (clone UB2; MBL, Nagoya, Japan); and mouse anti-human CD120a monoclonal antibody (Genzyme, Cambridge, MA, USA).

Flow cytometric analyses of smooth muscle actin. Flow cytometric analyses of smooth muscle actin (SMA) were performed as follows. Cells were detached from culture flasks with $3 \mathrm{mM}$ EDTA in PBS, and washed with wash buffer (PBS containing $2 \%$ FCS). The cells were fixed with $4 \%$ paraformaldehyde in $0.1 \mathrm{M} \mathrm{NaH}_{2} \mathrm{PO}_{4}$ ( $\mathrm{pH}$ 7.4) for $10 \mathrm{~min}$ on ice. After two washes with wash buffer, the cells were treated with $100 \mathrm{mg} / \mathrm{ml}$ digitonin (Sigma Chemical Co.) for $10 \mathrm{~min}$ at room temperature. After another two washes, the cells were treated with normal mouse $\mathrm{IgG}$ to block non-specific binding sites for $5 \mathrm{~min}$ at room temperature, followed by incubation with a mouse anti-SMA monoclonal antibody (clone 1A4; Neomarkers, Fremont, CA, USA) for $30 \mathrm{~min}$ at room temperature and two further washes. Finally, the cells were incubated in FITCconjugated goat anti-mouse IgG (Gibco BRL) for $30 \mathrm{~min}$ at room temperature, washed twice and suspended in $200 \mu \mathrm{l}$ of wash buffer for analyses using a FACSCalibur (Beckman Coulter, Japan).

Anticancer drugs. All anticancer drugs were kind gifts from pharmaceutical companies. SN38, a major active metabolite of irinotecan- $\mathrm{HCl}$ (CPT-11), was obtained from Yakult Honsha Co. Ltd. (Tokyo, Japan). Mitomycin C (MMC) and 5-fluorouracil (5FU) were provided by Kirin-Kyowa-Hakko Co. Ltd. (Tokyo, Japan). Paclitaxel (PTX), carboplatin (CBDCA) and etoposide (VP16) were provided by Bristol-Myers Squibb Japan Co. Ltd. (Tokyo, Japan). Pirarubicin-HCl (THP) was provided by Meiji-Seika Kaisha Ltd. (Osaka, Japan). Cisplatin (CDDP) and peplomycin (PM) were provided by Nihon-Kayaku Co. Ltd. (Tokyo, Japan). Docetaxel (DTX) was provided by Sanofi-Aventis Japan (Tokyo, Japan). Nedaplatin (NPL) was obtained from Shionogi \& Co. Ltd. (Osaka, Japan). Methotrexate (MTX) was obtained from Takeda Pharmaceutical Co. Ltd. (Osaka, Japan).

Anticancer drug-sensitivity assays. The effects of anticancer drugs on cell growth were assayed as follows. Cells in the log phase were detached with $0.25 \%$ trypsin/ $1 \mathrm{mM}$ EDTA (Gibco BRL) and cultured overnight in 96 -well plates $\left(5 \times 10^{3}\right.$ cells/ well). On day 2, various concentrations of anticancer drugs were added to the cells. On day 4, the numbers of viable cells were evaluated using a cell proliferation assay kit (Dojin, Tokyo, Japan) and expressed as the percentages of viable cells $(\%)$ relative to the mean number of viable untreated cells. All 
Extrauterine tumor (NW-1,2,3)

\begin{tabular}{|c|c|c|}
\hline (1) in vitro culture $5 \mathrm{M} \sim$ & $\begin{array}{l}\text { NW-1ive } \\
\text { NW-2ive } \\
\text { NW-3ive }\end{array}$ & $\begin{array}{l}\text { Not established } \\
\text { Not established } \\
\text { Established }\end{array}$ \\
\hline $\begin{array}{l}\text { (2) nude mice s.c. } \\
\text { transplantation } 7 \mathrm{M}\end{array}$ & $\begin{array}{l}\text { NW-1sc } \\
\text { NW-2sc } \\
\text { NW-3sc }\end{array}$ & $\begin{array}{l}\text { Not established } \\
\text { Not established } \\
\text { Not established }\end{array}$ \\
\hline $\begin{array}{l}\text { (3) nude mice i.p. } \\
\text { transplantation } 7 \mathrm{M}\end{array}$ & $\begin{array}{l}\text { NW-1ip } \\
\text { NW-2ip } \\
\text { NW-3ip }\end{array}$ & $\begin{array}{l}\text { Not established } \\
\text { Not established } \\
\text { Not established }\end{array}$ \\
\hline
\end{tabular}

Intrauterine tumor (NW-4,5)

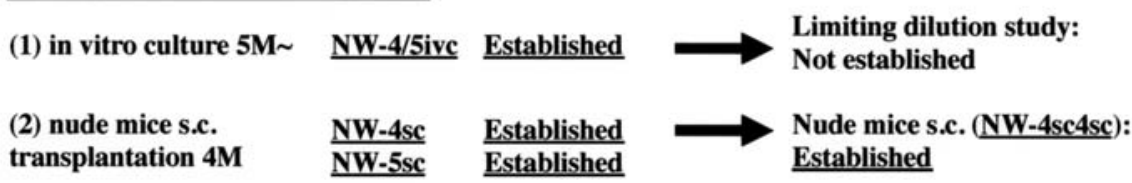

$\begin{array}{lll}\text { (3) nude mice i.p. } & \text { NW-4ip } & \text { Not established } \\ \text { transplantation 7M } & \text { NW-5ip } & \text { Not established }\end{array}$

Figure 1. Procedure for establishing the NW series of uterine leiomyosarcoma cell lines. The NW cell lines were established from extrauterine and intrauterine tumors from a single patient as shown in the chart.

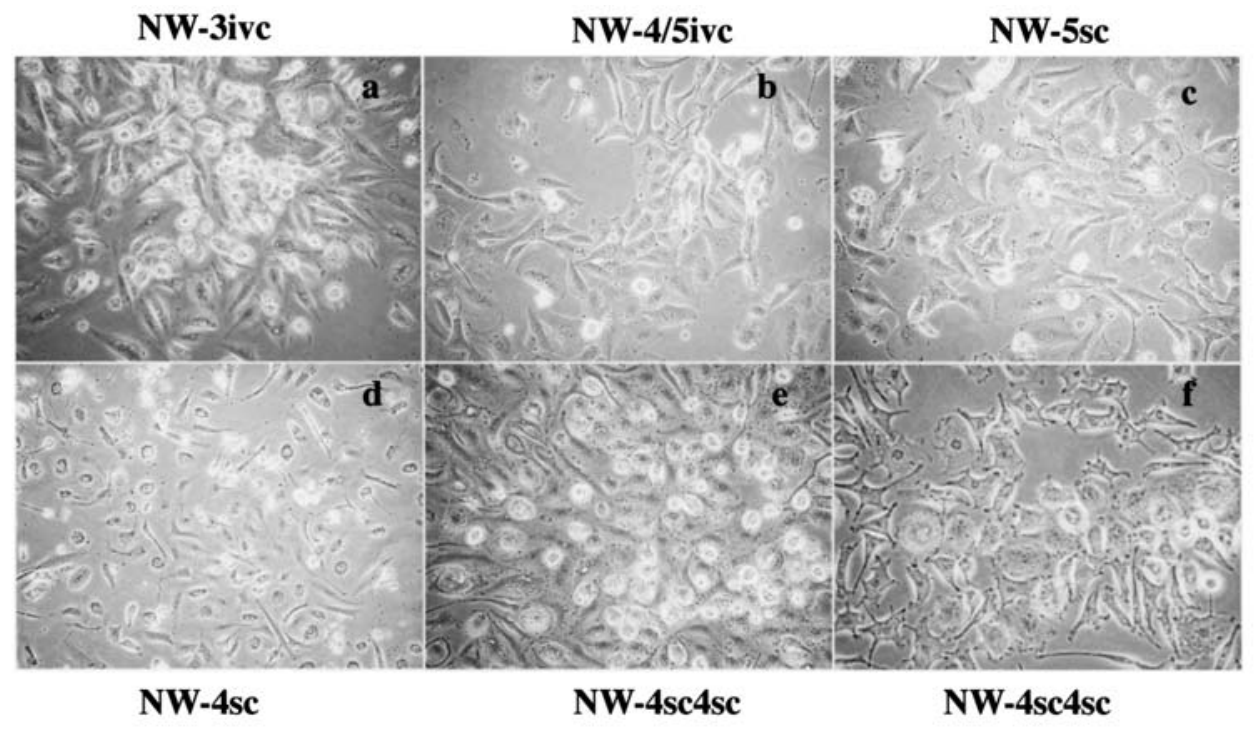

Figure 2. Microscopic findings of in vitro-cultured NW cells. (a) NW-3ivc cells. (b) NW-4/5ivc cells. (c) NW-5sc cells. (d) NW-4sc cells. (e and f) NW-4sc4sc cells. Magnification x400.

experiments were performed in triplicate. Data are expressed as the mean $\pm S D$, and comparative data $(n=6)$ were analyzed by ANOVA.

Karyotyping analysis. Cytogenetic analyses were performed according to previously reported methods $(3,4)$ with the following modifications. Briefly, tumor cell cultures were washed and incubated with $0.1 \% \mathrm{v} / \mathrm{v}$ colcemide (Sigma Chemical Co.) overnight. The cells were then exposed to a hypotonic solution composed of $3 \mathrm{~g} / 1 \mathrm{KCl}, 0.2 \mathrm{~g} / \mathrm{l} \mathrm{EGTA}$ and $4.8 \mathrm{~g} / \mathrm{l}$ HEPES. The cells were centrifuged into a pellet and fixed in a methanol solution. G-banding was performed using the method of Yunis (5).

\section{Results}

Establishment of primary human uterine leiomyosarcoma cell lines. Fig. 1 shows the experimental process used to establish the primary human uterine leiomyosarcoma cell lines, designated the NW series. Using primary tumors surgically excised from the patient, we tried to establish cell lines from three extrauterine tumors (NW-1, NW-2 and NW-3) and two intrauterine tumors (NW-4 and NW-5).

Several tissue fragments from the three extrauterine tumors (NW-1, NW-2 and NW-3) were subcutaneously transplanted into the back skin of nude mice (NW-1sc, NW-2sc and NW-3sc, respectively). The remaining parts of the three 


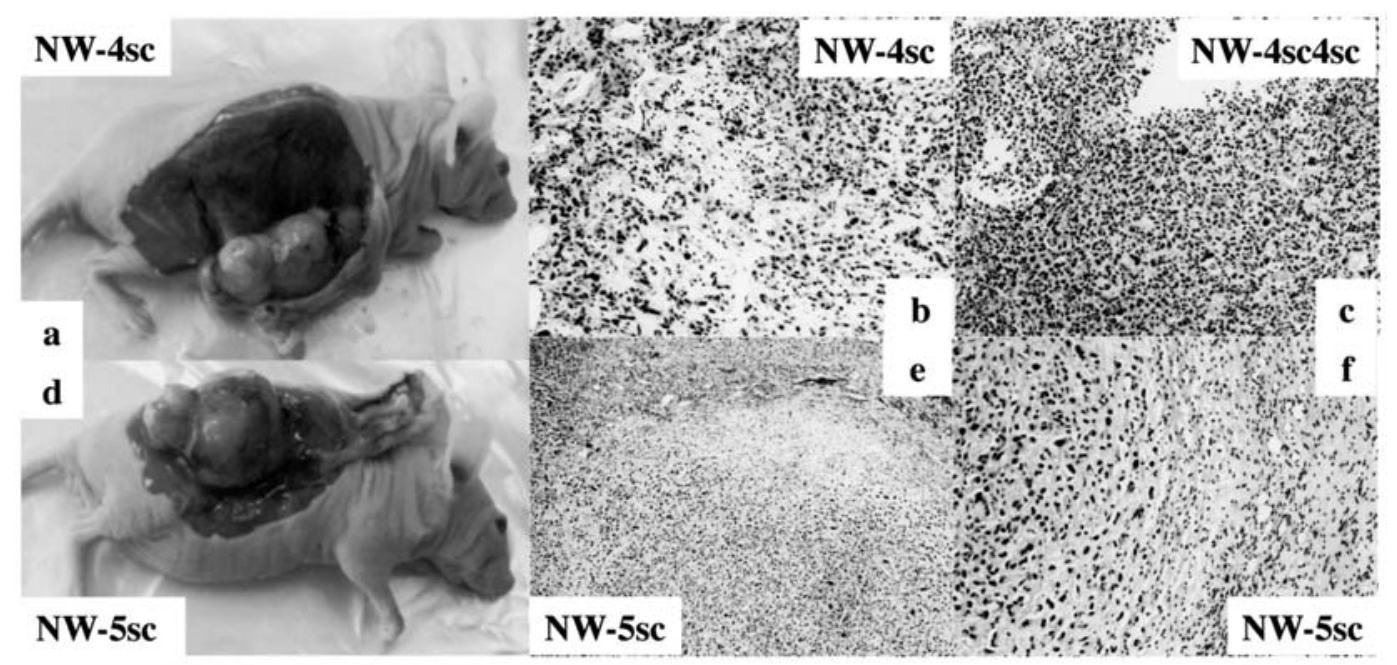

Figure 3. Transplantation of NW cells into nude mice. The tumors in nude mice transplanted subcutaneously with NW cells contain human leiomyosarcoma tissues. (a) NW-4sc-bearing nude mouse. (b) Histopathological findings for an HE-stained section of the NW-4sc nude mouse tumor (magnification x200). (c) Histopathological findings for an HE-stained section of the NW-4sc4sc nude mouse tumor (magnification x200). (d) NW-5sc-bearing nude mouse. (e and f) Histopathological findings for HE-stained sections of the NW-5sc nude mouse tumor (magnification: e, x100; f, x200).

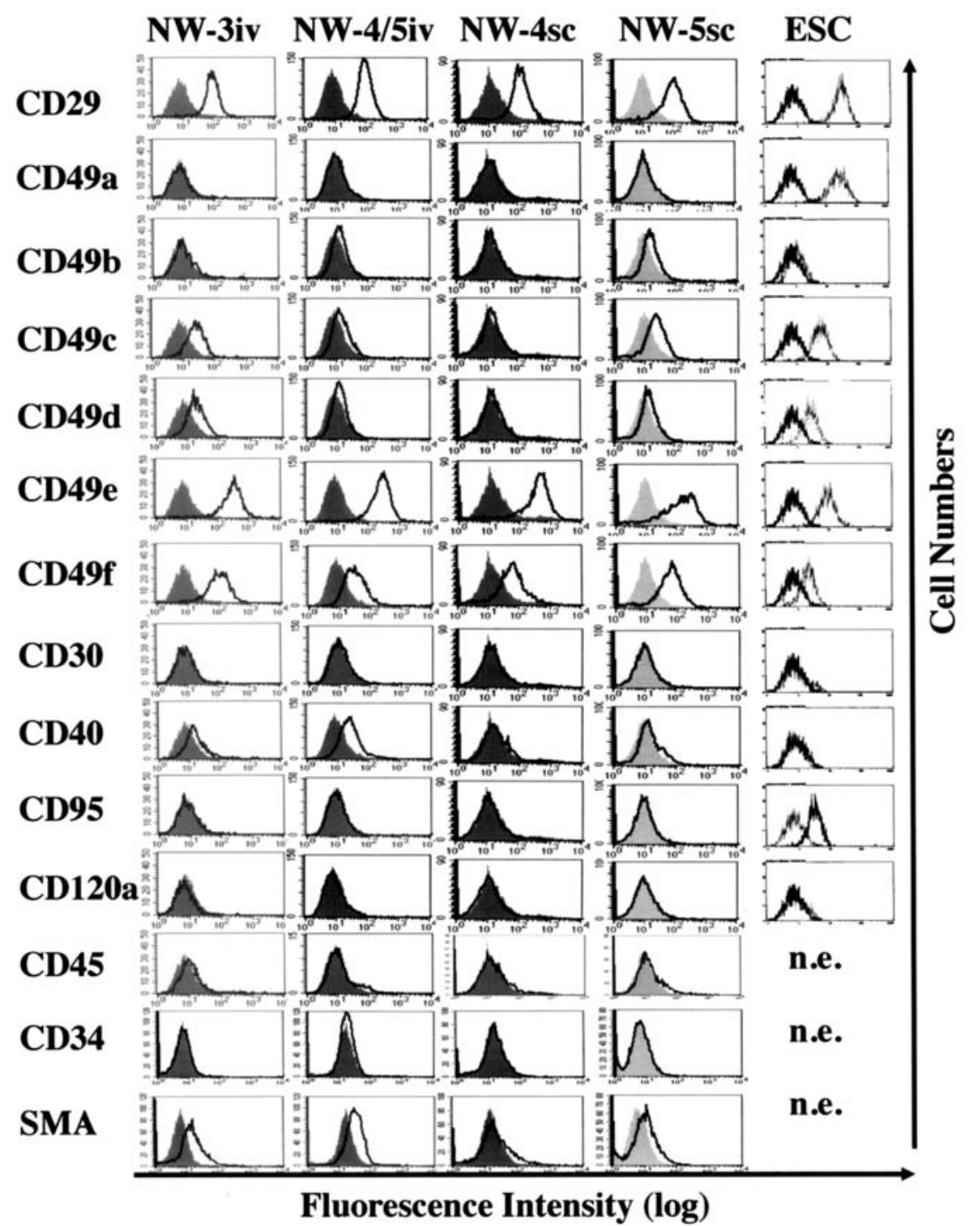

Figure 4. Flow cytometric analyses of the NW cell lines. In the panels for the NW-3ivc, NW-4/5ivc, NW-4sc and NW-5sc cell lines, the dark gray histograms show negative controls and the white histograms show positive reactions. In the panels for ESCs, the thick histograms show negative controls and the thin histograms show positive reactions. n.e., not examined. 


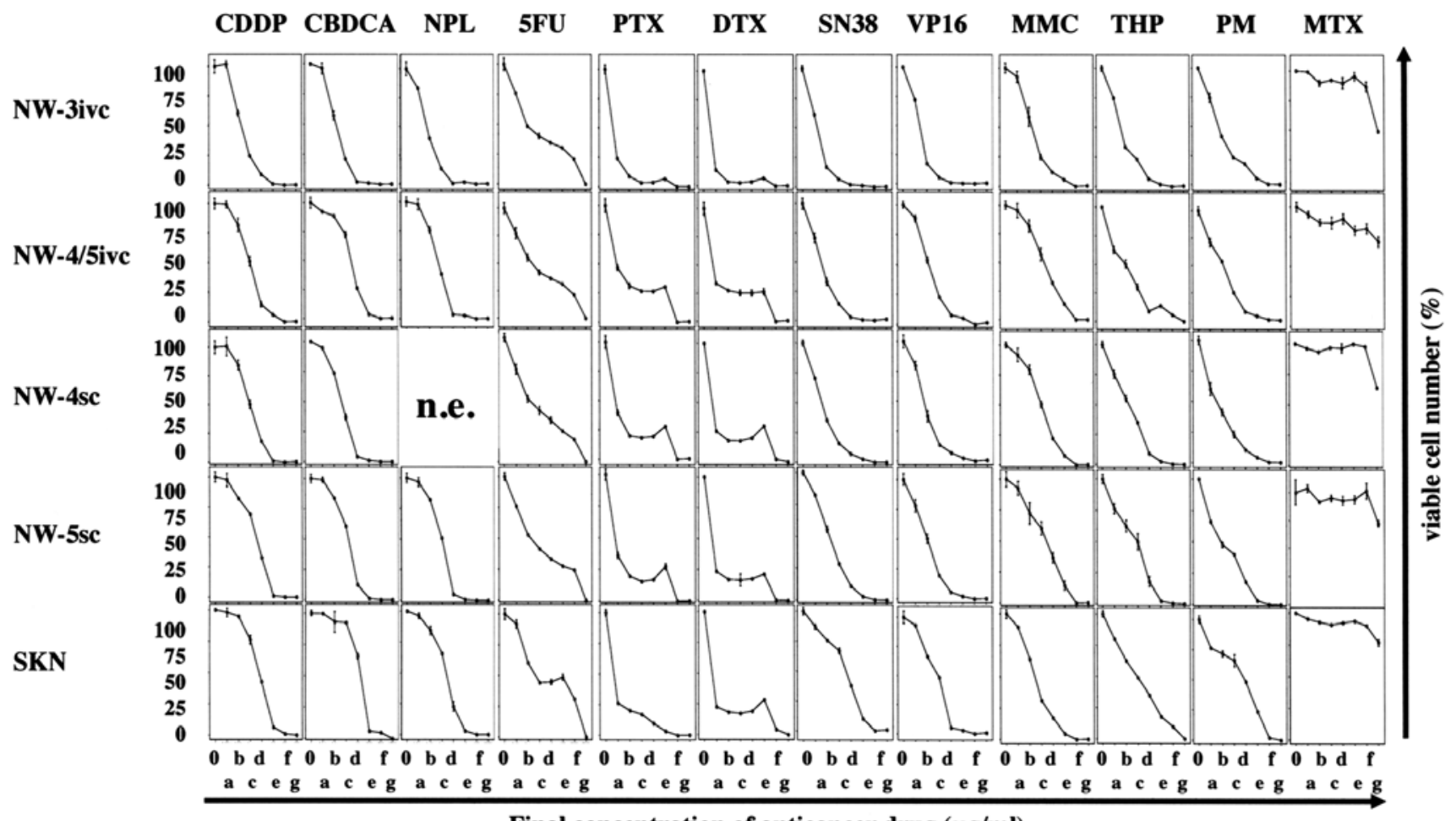

Final concentration of anticancer $\mathrm{drug}(\mu \mathrm{g} / \mathrm{ml})$

Figure 5. Anticancer drug-sensitivity assays of the NW cell lines. The anticancer drug-sensitivity assays of the NW-3ivc, NW-4/5ivc, NW-4sc, NW-5sc and SKN cell lines were compared. The final concentrations $(\mu \mathrm{g} / \mathrm{ml})$ of each anticancer drug indicated as 0 and a-g at the bottom of the figures were as follows. CDDP: $0,0.016,0.08,0.4,2,10,50$ and $250 \mu \mathrm{g} / \mathrm{ml}$. CBDCA: 0, 0016, 0.8, 4, 20, 100, 500 and 2500 $\mu \mathrm{g} / \mathrm{ml}$. NPL: 0, 0.064, 0.032, 1.6, 8, 40, 200 and 1000 $\mu \mathrm{g} / \mathrm{ml}$. 5FU: 0, 0.32, 1.6, 8, 40, 200, 1000 and 5000 $\mu \mathrm{g} / \mathrm{ml}$. PTX: 0, 0.0064, 0.032, 0.16, 0.8, 4, 20 and $100 \mu \mathrm{g} / \mathrm{ml}$. DTX: 0,0.0064, 0.032, 0.16, 0.8, 4, 20 and 100 $\mu \mathrm{g} / \mathrm{ml}$. SN38: 0, 0.00064, 0.0032, 0.016, 0.08, 0.4, 2 and $10 \mu \mathrm{g} / \mathrm{ml}$. VP16: 0, 0.128, 0.64, 3.2, 16, 80, 400 and 2000 $\mu \mathrm{g} / \mathrm{ml} . \mathrm{MMC}: 0,0.064,0.032,0.16,0.8,4,20 \mathrm{and}$ $100 \mu \mathrm{g} / \mathrm{ml}$. THP: 0, 0.00064, 0.0032, 0.016, 0.08, 0.4, 2 and $10 \mu \mathrm{g} / \mathrm{ml}$. PM: 0, 0.16, 0.8, 4, 20, 100, 500 and 2500 $\mu \mathrm{g} / \mathrm{ml}$. MTX: 0, 0.0025, 0.025, 0.25, 2.5, 25, 250 and $2500 \mu \mathrm{g} / \mathrm{ml}$. n.e., not examined.

extrauterine tumor tissues were independently digested with collagenase, and cultured in vitro (NW-1ivc, NW-2ivc and NW-3ivc, respectively). After 5 days of culture, some of these cells were intraperitoneally transplanted into nude mice (NW-1ip, NW-2ip and NW-3ip, respectively). Although we observed the nude mice for $>7$ months, no tumor growths were detected in the peritoneal cavity (NW-1ip, NW-2ip and NW-3ip) or subcutaneous tissue (NW-1sc, NW-2sc and NW-3sc). These mice survived without any problems. Among the three in vitro-cultured extrauterine tumors (NW-1ivc, NW-2ivc and NW-3ivc), only NW-3ivc was able to grow stably in vitro for $>5$ months (Fig. 2a). The established NW-3ivc cells grew dispersedly in a monolayer, without forming any sheet layers, and exhibited strong attachment to the culture dishes. A limiting dilution study to identify monoclonal stem-like tumor cells among the NW-3ivc cells was tried but no tumor cell growth was detected, even in cultures at 40 cells/well.

Several tissue fragments from the two intrauterine tumors (NW-4 and NW-5) were subcutaneously transplanted into the back skin of nude mice (NW-4sc and NW-5sc, respectively). The remaining parts of the two intrauterine tumor tissues were digested with collagenase, and cultured in vitro (NW-4/ 5ivc). After 5 days of culture, some of these cells were intraperitoneally transplanted into nude mice (NW-4ip and NW-5ip, respectively). Although we observed the nude mice for $>7$ months, no tumor growths were detected in the peritoneal cavity (NW-4ip and NW-5ip). These mice survived without any problems. However, NW-4sc and NW-5sc cells formed large subcutaneous tumors on the backs of nude mice after 4 months (Fig. 3a and d). Histopathological examinations of the nude mouse tumors (NW-4sc and NW-5sc) revealed human leiomyosarcoma tissues with many mitotic nuclei (Fig. 3b, e and f). Re-transplantation of small tissue fragments from the NW-4sc tumor into the back of a nude mouse led to the formation of large tumors within 2 months (NW-4sc4sc). None of the tumor-bearing mice (NW-4sc, NW-5sc and $\mathrm{NW}-4 \mathrm{sc} 4 \mathrm{sc}$ ) showed any carcinomatous peritonitis, distant metastatic lesions in the lungs and liver or cachexic conditions. Histopathological examinations of the NW-4sc4sc nude mouse tumors revealed the same sarcoma tissue as the NW-4sc nude mouse tumors (Fig. 3c).

NW-4/5ivc cells (NW-4ivc and NW-5ivc) were able to grow stably in vitro for $>5$ months (Fig. 2b). All the nude mouse tumor cells (NW-4sc, NW-5sc and NW-4sc4sc) were able to grow in vitro and showed similar microscopic findings to NW-3ivc and NW-4/5ivc cells (Fig. 2c-f). Limiting dilution studies to identify monoclonal stem-like tumor cells among NW-4/5ivc, NW-4sc, NW-5sc and NW-4sc4sc cells were tried but no tumor cell growth was detected, even in cultures at 40 cells/well. All the in vitro-cultured cells (NW-3ivc, NW-4/5ivc, NW-4sc, NW-5sc and NW-4sc4sc) attached to 
culture dishes strongly enough to require scraping in addition to trypsin/EDTA treatment for their removal from the culture dishes.

Flow cytometric analysis of antigen expressions in the NW cell lines. The cell surface antigen expression profiles on four in vitro-cultured cell lines (NW-3ivc, NW-4/5ivc, NW-4sc and NW-5sc) were investigated by flowcytometry. The flow cytometric data of normal human ESCs were compared with those of the NW cell lines. There were no apparent differences among the flow cytometric profiles of NW-3ivc, NW-4/5ivc, NW-4sc and NW-5sc (Fig. 4). All four NW cell lines showed higher levels of CD49e and CD49f expression and lower levels of CD49a, CD49c and CD49d expression compared with the levels in ESCs (Fig. 4).

Anticancer drug-sensitivity assays of the NW cell lines. Anticancer drug-sensitivity assays against 12 anticancer drugs were performed on four in vitro-cultured cells (NW-3ivc, NW-4/5ivc, NW-4sc and NW-5sc) and the well-known human uterine leiomyosarcoma cell line SKN. As shown in Fig. 5, all the drug-sensitivity curves for the four NW cell lines showed almost the same results as those for SKN cells. The extrauterine tumor-derived NW-3ivc cells showed slightly higher sensitivity curves than the intrauterine tumorderived NW cells (NW-4/5ivc, NW-4sc and NW-5sc).

Karyotyping analyses of the NW cell lines. Karyotyping analyses of four in vitro-cultured NW cells (NW-3ivc, NW-4/ 5ivc, NW-4sc and NW-5sc) were examined. The karyotype of NW-3ivc cells was 120, XX, $\operatorname{add}(\mathrm{X})(\mathrm{q} 28) \mathrm{x} 2 \operatorname{add}(1)(\mathrm{p} 11)$, $\operatorname{add}(1)(\mathrm{p} 11), \operatorname{add}(1)(\mathrm{q} 11), \operatorname{add}(1)(\mathrm{q} 11),-2,+\operatorname{add}(3)(\mathrm{p} 13)$, $\operatorname{add}(3)(\mathrm{q} 27) \times 2,-4, \operatorname{add}(4)(\mathrm{p} 16),-5,-6,-6, \operatorname{der}(6) \operatorname{del}(6)(\mathrm{p} 23)$ $\operatorname{del}(6)(\mathrm{q} 13), \operatorname{add}(7)(\mathrm{p} 11) \times 2,-8, \operatorname{add}(9)(\mathrm{p} 11), \operatorname{add}(9)(\mathrm{p} 22)$, $\operatorname{add}(9)(q 34),-10,-10,+\operatorname{add}(11)(\mathrm{p} 15),-12,-13,-14,-15$, $+\operatorname{add}(16)(\mathrm{p} 11),+\operatorname{add}(16)(\mathrm{p} 13) \times 2,-17,-17,+18,-19,-19,-19$, $-19,-20,+21,+21,+21,+22,+22,+\operatorname{add}(22)(\mathrm{q} 11) \times 2,+34 \mathrm{mar}$, $\sim 5 \mathrm{dmin}$ (Fig. 6a). The karyotype of NW-4/5ivc cells was $110, X X,+\operatorname{add}(X)(q 28) \times 2, \operatorname{del}(X)(q 22) \times 2,+\operatorname{add}(1)(\mathrm{p} 11)$, $\operatorname{add}(1)(\mathrm{p} 11), \operatorname{add}(1)(\mathrm{q} 11), \operatorname{add}(1)(\mathrm{q} 11), \operatorname{der}(1) \operatorname{add}(1)(\mathrm{p} 36)$ $\operatorname{add}(1)(\mathrm{q} 11),-2, \operatorname{add}(3)(\mathrm{q} 27) \times 2, \operatorname{add}(3)(\mathrm{q} 27),+\operatorname{add}(4)(\mathrm{p} 16)$, $\operatorname{add}(4)(\mathrm{q} 31),-5, \operatorname{add}(5)(\mathrm{q} 15), \operatorname{del}(6)(\mathrm{q} 13),+7, \operatorname{del}(7)(\mathrm{p} 11) \times 2$, $-8,-8, \operatorname{add}(9)(\mathrm{q} 34) \times 2,-10,-10, \operatorname{add}(10)(\mathrm{p} 11),-11,-13,-14,-14$, $-15,-15,-15,+\operatorname{add}(16)(\mathrm{p} 13) \times 2,-17, \operatorname{add}(17)(\mathrm{q} 23) \times 3,-18$, $\operatorname{add}(18)(\mathrm{q} 21),-19,-19,-19,+20,+21,+21,+22,+22,+22$, $+22,+22 \mathrm{mar}, \sim 16 \mathrm{dmin}$ (Fig. 6b). The karyotype of NW-4sc cells was 61, XX, $+\operatorname{del}(\mathrm{X})(\mathrm{q} 22),+\operatorname{add}(1)(\mathrm{p} 11), \operatorname{add}(1)(\mathrm{q} 11)$, $\operatorname{add}(1)(q 11), \operatorname{add}(3)(q 27), \operatorname{add}(3)(q 27),+\operatorname{add}(4)(\mathrm{p} 16),-5$, $+\operatorname{add}(6)(\mathrm{p} 25), \operatorname{add}(7)(\mathrm{p} 22),+\operatorname{add}(9)(\mathrm{q} 34), \operatorname{add}(10)(\mathrm{p} 11)$, $\operatorname{add}(10)(q 26), \operatorname{add}(11)(\mathrm{p} 15), \operatorname{add}(16)(\mathrm{p} 13), \operatorname{add}(17)(\mathrm{q} 23) \times 2$, $\operatorname{add}(18)(q 23),-19,+\operatorname{add}(20)(q 11),+22,10 \mathrm{mar}, \sim 7 \mathrm{dmin}$ (Fig. 6c). The karyotyping analysis of NW-5sc cells showed incomplete data because of their slow growth except for the mean chromosome number of 70 (data not shown).

\section{Discussion}

We have succeeded in establishing five novel human uterine leiomyosarcoma cell lines, NW-3ivc, NW-4/5ivc, NW-4sc, $\mathrm{NW}-5 \mathrm{sc}$ and $\mathrm{NW}-4 \mathrm{sc} 4 \mathrm{sc}$, that can be cultured in vitro and are a.

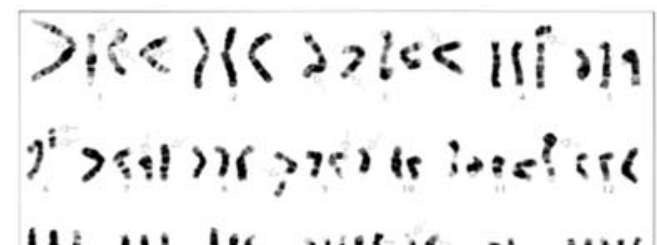

NW-3ivc

b.

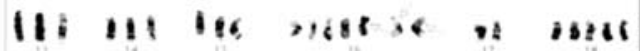

.

NW-4/5ivc

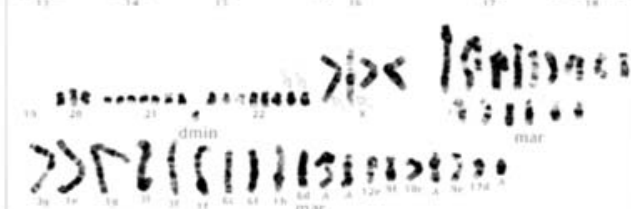

म.t

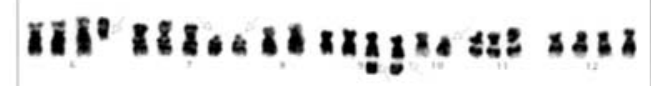

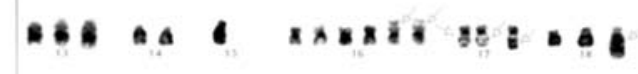

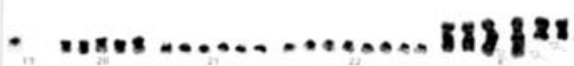

Uhimbtw, a....."

c.

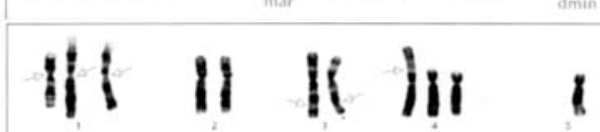

NW-4sc

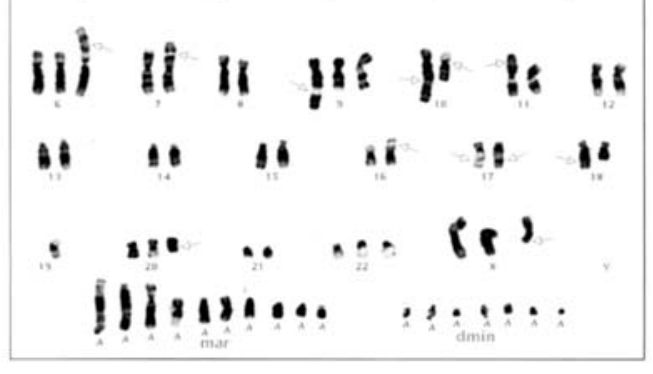

Figure 6. Karyotyping analyses of NW cells. (a) Karyotype of NW-3ivc cells. (b) Karyotype of NW-4/5ivc cells. (c) Karyotype of NW-4sc cells.

able to form tumors in nude mice. These cell lines will be useful for investigating potential therapies for uterine leiomyosarcoma patients. Moreover, this is the first study to simultaneously establish different cell lines derived from extrauterine and intrauterine tumors from a single patient. This is also the first study to establish in vitro-cultured cell lines and nude mouse-transplanted cell lines from one leiomyosarcoma patient. These cell lines can be used to investigate differences in the characteristics of extrauterine and intrauterine leiomyosarcoma cells, and to characterize the tumor-forming leiomyosarcoma cells in nude mice.

When we had established our novel human uterine leiomyosarcoma cell lines, we were unable to achieve any tumor progression by intraperitoneal injections of the tumor cells into nude mice. Although several in vitro-cultured cell lines were established, no monoclonal leiomyosarcoma cell lines were obtained by limiting dilution studies. Subcutaneous transplantation of small tissue fragments derived from the extrauterine leiomyosarcoma tissues did not lead to any tumor growth in the back of nude mice, while subcutaneous transplantation of small tissue fragments from the intrauterine 
tumors led to tumor growth in the back of nude mice. Tumor cells from the subcutaneous nude mouse tumors were successfully cultured in vitro, but no monoclonal leiomyosarcoma cell lines were established by limiting dilution studies. None of the tumor-bearing nude mice showed any carcinomatous peritonitis, lung metastases, liver metastases or cachexic malnutrition. These findings suggest that some of the characteristics of NW cell lines are difficulties in causing carcinomatous peritonitis or distant metastases at the early stage. The failures of our limiting dilution studies also suggest that NW cells cannot easily grow from one cell and that NW cells may need some essential growth factors. The successful transplantation of tissue fragments into nude mice may suggest that several kinds of sarcoma fragments can proliferate together in autocine/paracrine manners with unknown essential growth factors. Intraperitoneal injections of dispersed sarcoma cells together did not succeed in causing carcinomatous peritonitis in nude mice, indicating the possibilities that the essential growth factors are hardly produced in the peritoneal cavity and that NW leiomyosarcoma cells cannot bind tightly to the murine peritoneum. The proliferation rates of the nude mouse tumors (NW-4sc and NW-5sc) were much slower than those of human leiomyosarcoma tissues in the human body, suggesting that the essential growth factors may have high species-specificity.

Regarding the microscopic findings, NW cells proliferated in monolayers with loose intracellular adhesiveness, but exhibited strong attachment to culture dishes. Stable proliferation of NW cells may require strong adhesion to certain extracellular matrices. Unique very late antigen (VLA) expressions such as higher VLA-5 (CD29/CD49e) and VLA-6 (CD29/CD49f) expressions may be associated with specific proliferation of NW cells. The adhesion of NW cells to culture dishes could not be disrupted by treatment with trypsin/EDTA alone and required scraping, indicating that NW cells possess strong $\mathrm{Ca}^{2+}$-independent cell adhesion.

It is well known that neither radiotherapy nor anticancer chemotherapy has clinical therapeutic effects on patients with primary uterine leiomyosarcoma. When the tumor cannot be radically resected from advanced uterine leiomyosarcoma patients, these patients have an extremely poor prognosis. There are few reports of complete cures of advanced uterine leiomyosarcoma patients by chemotherapy and/or radiotherapy. The anticancer drug sensitivities of the NW cell lines against 12 anticancer drugs were almost the same as those of SKN cells. In fact, the 50\% viability-inhibitory concentrations of the anticancer drugs in the NW cell lines were not lower than those in other uterine cancer cell lines $(6,7)$ and ovarian cancer cell lines $(8,9)$ that were assayed by the same method used in the present study. These findings suggest that the first exposure of NW cells to anticancer drugs may have high chemotherapeutic effects. Since there were numerous differential chromosomal mutations in NW-3ive, NW-4/5ivc and NW-4sc cells, the chromosomal structures of NW cells are sufficiently unstable to be able to mutate easily during anticancer chemotherapy. The major clinical problem that uterine leiomyosarcoma patients show much lower sensitivities to chemotherapy and radiotherapy may be caused by this chromosomal instability.

\section{References}

1. Ishiwata I, Nozawa S, Nagai S, Kurihara S and Mikata A: Establishment of a human leiomyosarcoma cell line. Cancer Res 37: 658-664, 1977.

2. Tanaka T, Nakajima S and Umesaki N: Cellular heterogeneity in long-term surviving cells isolated from eutopic endometrial, ovarian endometrioma and adenomyosis tissues. Oncol Rep 10: 1150-1160, 2003.

3. Gibas Z, Prout GR, Conolly JG, Pontes JE and Sandberg AA: Non-random chromosome changes in transitional cell carcinoma of the bladder. Cancer Res 44: 1257-1264, 1984.

4. Toshida MA, Ohyashiki K, Ochi H, Gibas Z, Pontes JE, Prout GR, Huben R and Sandberg AA: Cytogenetic studies of tumor tissue rom patients with non-familial renal cell carcinoma. Cancer Res 46: 2139-2147, 1986.

5. Yunis JJ: New chromosome techniques in the study of human neoplasia. Hum Pathol 12: 540-549, 1981.

6. Tanaka T, Toujima S, Otani T, Minami S, Yamoto M and Umesaki N: Expression and function of activin receptors in human endometrial adenocarcinoma cells. Int J Oncol 23: 657-663, 2003.

7. Bai T, Tanaka T, Yukawa $\mathrm{K}$ and Umesaki N: A novel mechanism for acquired cisplatin-resistance: suppressed translation of death-associated protein kinase mRNA is insensitive to 5-aza-2'deoxycitidine and trichostatin in cisplatin-resistant cervical squamous cancer cells. Int J Oncol 28: 497-508, 2006.

8. Tanaka T, Toujima S and Umesaki N: Growth-inhibitory signals by activin A do not affect anticancer drug-sensitivity and acquired multi-drug-resistance in human ovarian endometrioid adenocarcinoma OVK-18 cells. Oncol Rep 11: 667-671, 2004.

9. Tanaka T, Toujima S, Utsunomiya T, Yukawa K and Umesaki N: Experimental characterization of recurrent ovarian immature teratoma cells after optimal surgery. Oncol Rep 20: 13-23, 2008. 